\title{
Single access laparoscopic cholecystectomy: technique without the need for special materials and with better ergonomics
}

\section{Colecistectomia videolaparoscópica através de acesso único: técnica sem necessidade de materiais especiais e melhor ergonomia}

Marco Aurélo lameirão Pinto, TCBC-RJ'; Raphael Fernando Costa Gomes de Andrade'; Luiz Gustavo de Oliveira e Silva, TCBCRJ'; Marco Aurélio de Lacerda Pinto²; Roberto Jamil Muharre, TCBC-RJ'; Ricardo Ary Leal, TCBC-RJ'

\section{A}

\begin{abstract}
The authors describe a surgical technique which allows, without increasing costs, to perform laparoscopic cholecystectomy with a single incision, without using specific materials and with better surgical ergonomics. The technique consists of a longitudinal umbilical incision, navel detachment, use of a permanent $10 \mathrm{~mm}$ trocar and two clamps directly and bilaterally through the aponeurosis without the use of $5 \mathrm{~mm}$ trocars, transcutaneous gallbladder repair with straight needle cotton suture, ligation with unabsorbable suture and umbilical incision for the specimen extraction. The presented technique enables the procedure with conventional and permanent materials, improving surgical ergonomics, with safety and aesthetic advantages.
\end{abstract}

Key words: Cholecystectomy. Cholecystectomy, Laparoscopic. Video-Assisted Surgery.

\section{INTRODUCTION}

$\mathrm{T}^{\mathrm{h}}$ he first published laparoscopic cholecystectomy (LC) happened in 1987 by Phillipe Mouret, the year of publishing of the same procedure in France by Dubois and Perissat ${ }^{1,2}$. It was so successful that soon gained worldwide acceptance, being reproduced in many countries. In Brazil, the LC was first held at the Hospital Albert Einstein in Sao Paulo, by Thomas Szego ${ }^{3}$. Since then, laparoscopic surgery has become the gold standard for excision of the gallbladder ${ }^{4}$.

New less invasive techniques such as NOTES (Natural Orifice Transluminal Endoscopic Surgery) and the SILS (Single Incision Laparoscopic Surgery) have been proposed. However, such procedures require specific materials. SILS requires a single incision with three accesses for trocars (permanent or disposable) and curved forceps. This cause an increase in the procedure's cost, hindering its rapid expansion ${ }^{4,5}$.

Cholecystectomy through a single access has as advantages less postoperative pain and complications related to the extra incisions (infection, hematoma, bleeding and keloids), with better cosmetic results ${ }^{4,6}$. This technique more difficult to execute due to lack of triangulation and distance between incisions, as in the traditional laparoscopic route $^{7}$.

An alternative to the original SILS technique is proposed, aimed at reducing costs and improving surgical ergonomics, allowing the realization of this procedure in any center that has access to traditional laparoscopic surgical materials and staff trained in laparoscopic surgery.

\section{TECHNICAL ASPECTS}

The patient set in supine position with legs abducted and the operating table in reverse Trendelemburg (cranial elevation) and discrete left lateral decubitus. The staff must be positioned such that the surgeon is between the patient's legs, the first auxiliary on the left, and the second, on the right. The monitor should be left by the patient's right shoulder level.

A transumbilical, longitudinal incision of about 3 $\mathrm{cm}$ is carried out within the limit of the umbilical margins (size changed according to patient's anatomy). The skin is then dissected bilaterally, its edges are everted and secured with 3-0 nylon suture to reduce the skin damage caused by the surgical incision (Figure 1). Dissection by planes is performed until reaching the aponeurosis, with an exposure of $9 \mathrm{~cm}^{2}(3 \mathrm{~cm}$ in the longitudinal axis and $3 \mathrm{~cm}$ in the transverse one). The repair of the aponeurosis is done bilaterally, $1 \mathrm{~cm}$ lateral to the umbilical ligament, with 0 prolene suture.

The aponeurosis is incised in the midline and pneumoperitoneum is instilled by open technique with

1. Clínica cirúrgica II do Hospital Federal de Bonsucesso, Rio de Janeiro, Brasil; 2. Complexo Hospitalar de Niterói, Rio de Janeiro, Brasil. 
a $10 \mathrm{~mm}$ permanent trocar and $12 \mathrm{mmHg}$ pressure. Two new incisions are made in the anterior aponeurosis of the rectus abdominis muscle, bilaterally, both $1.5 \mathrm{~cm}$ cranial and $1.5 \mathrm{~cm}$ lateral to the $10 \mathrm{~mm}$ trocar. Through the trocar is inserted a $10 \mathrm{~mm}, 30^{\circ}$ angle endoscope; a conventional grasper clamp is introduced directly on the left side incision; through the right side incision are inserted clamps for dissection, repair and ligatures (Figure 2).

For an adequate examination of the cavity we introduce a conventional straight Maryland forceps. After identification of the gallbladder and lysis of possible adhesions, traction ids applied to the gallbladder towards the anterior abdominal wall by means of 2-0 cotton suture with straight needle inserted in the right subcostal region over the mid-clavicular line. This repair is performed in the gallbladder wall between the fundus and the body, with the return of the needle to the external environment (Figure 3). The cotton suture is pulled by the second auxiliary and fixed by a straight Kelly forceps, keeping the gallbladder tensioned (Figure 4). The dissection of the gallbladder pedicle starts with a grasper through the left incision for mobilization and exposure of the operative field and a conventional hook through the right incision for careful dissection.

After isolation of the cystic duct and cystic artery, we proceed to their ligations with 2-0 polypropylene suture using the extracavitary knot technique and adjusting with a knot pusher.

Afterwards, we dissect the gallbladder from the liver bed and hold a hemostasis review. We then release the cotton suture repair and remove it. With a grasper, we bring the gallbladder to the midline incision. We withdraw the $10 \mathrm{~mm}$ trocar and extend the incision for direct visualization of the repair and removal of the gall bladder without difficulty (Figure 5).

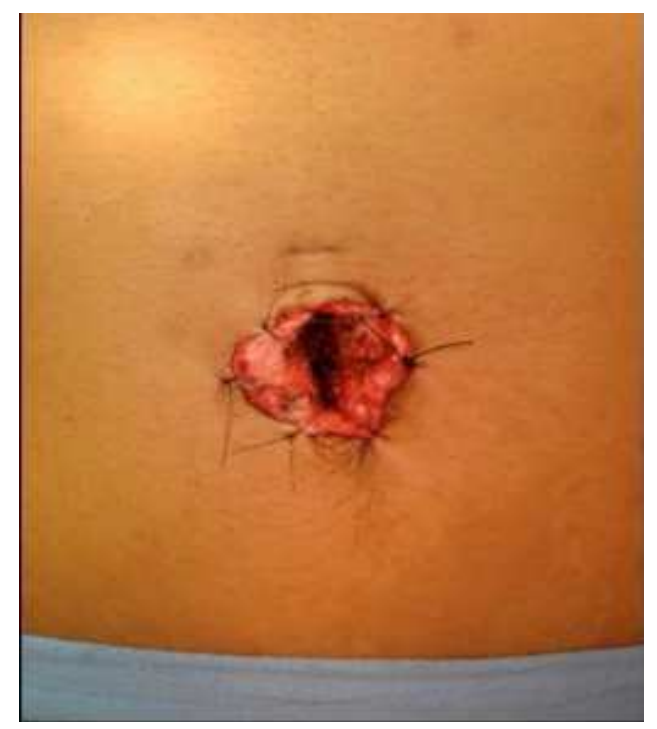

Figure 1 - Eversion of skin for protection.
Wound closure is performed with 0 prolene suture. The skin eversion stitches are cut and the navel repositioned with 2-0 nylon. The skin synthesis is performed with intradermic suture of 4-0 nylon (Figure 6).

\section{DISCUSSION}

With the advancement of technology after the advent of laparoscopy, new techniques have been developed to reduce surgical aggression and improve cosmetic results. Initially, the decrease in diameter and number of the ports was proposed. Then, natural orifices (NOTES) and a single access (SILS) procedures become the

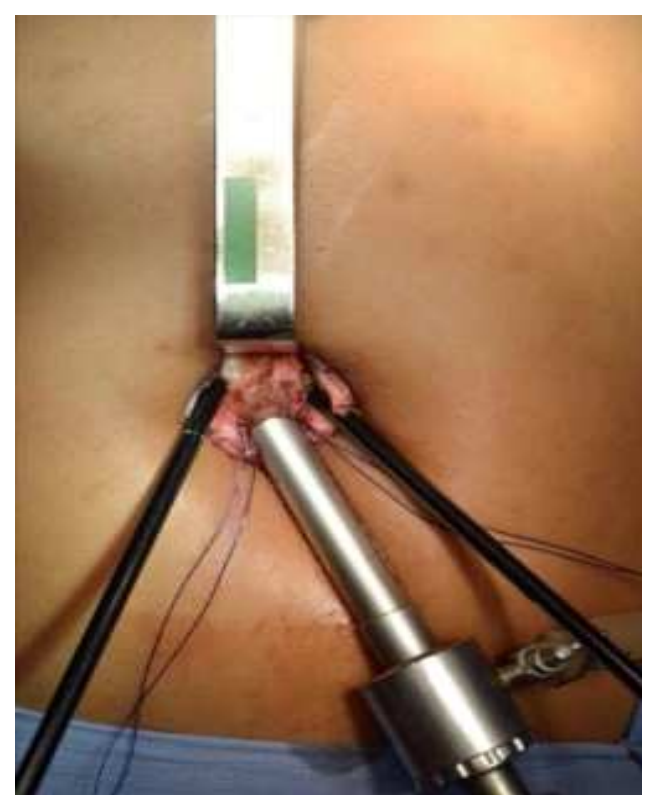

Figure 2 - Positioning of endoscope and clamps in the single incision.

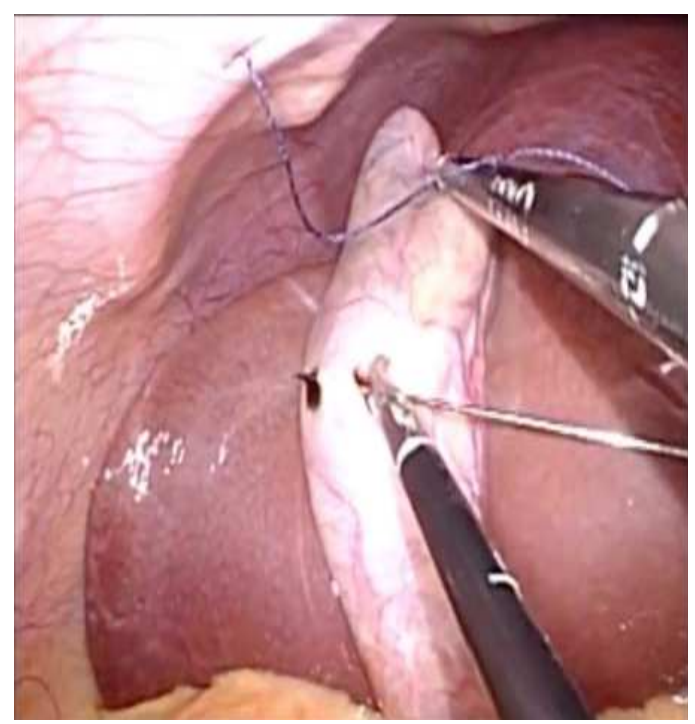

Figure 3 - Gallbladder repair stitch with a straight needle. 


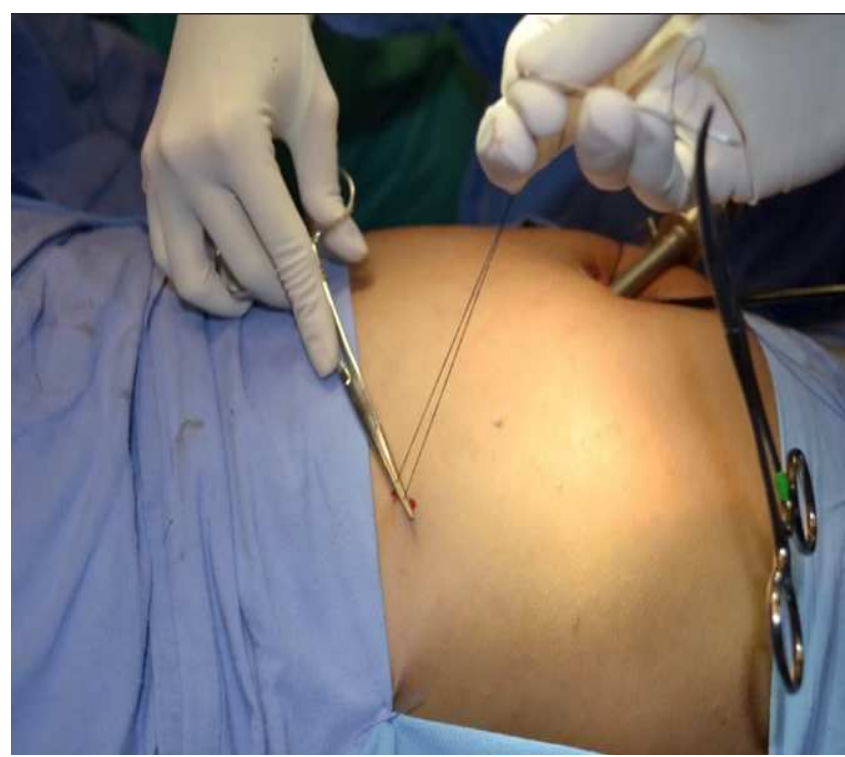

Figure 4 - Kelly clamp pulling the transcutaneous gallbladder repair.

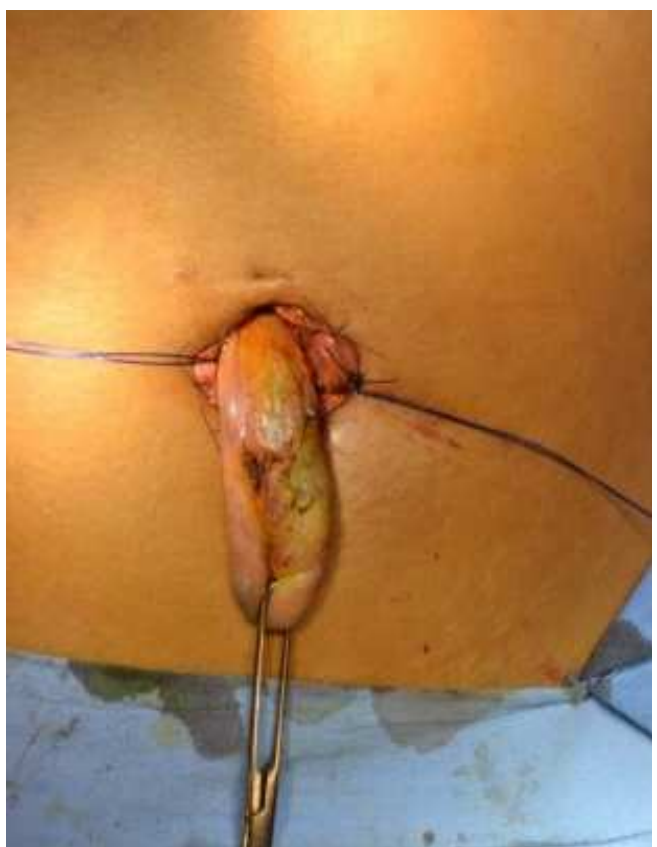

Figure 5 - Gallbladder being removed by single umbilical incision.

options with better aesthetic results ${ }^{8}$. The increase in enthusiasts of this new technique of single umbilical incision encouraged companies of surgical materials to develop a number of specific materials in order to improve its safety and ergonomics ${ }^{4,7}$. However, such materials are expensive.

Laparoscopic surgery has in its technical principles triangulation and traction and counter-traction, always allowing for lateralized vision ( $0^{\circ}$ or $30^{\circ}$ endoscope) and proper ergonomics to apply the necessary tractions. The difficulty of the single incision technique is the alignment of endoscope and clamps, decreasing the triangulation

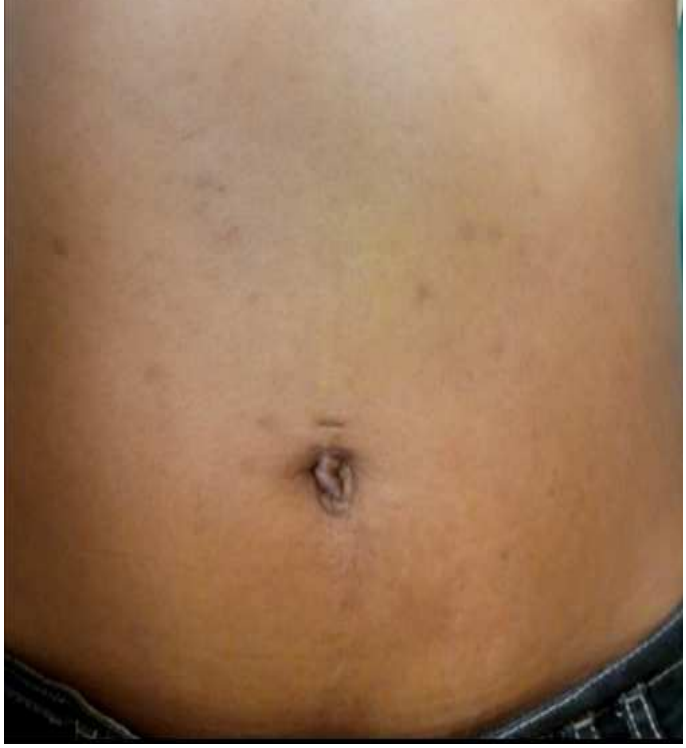

Figure 6 - Final aesthetic result.

capability. The idea of curved or articulated clamps and endoscope with angles of up to $90^{\circ}$ arose in the attempt to correct these obstacles, however adding a major increase in the procedure's cost ${ }^{7}$.

Despite the optical alignment with tongs, lower ergonomics and worse triangulation, cholecystectomy by single incision did not change the iatrogenic injury rates or the percentage of conversion, only increasing operating time ${ }^{9}$. It is worth noting that this technique also allows a conversion to conventional laparoscopy with four incisions before resorting to laparotomy.

Alternative lower cost techniques use conventional laparoscopic materials, allowing the realization of single access surgery at any center that has access to laparoscopy and has trained staff. However, such techniques still have a difficult ergonomics due to the passing of three trocars by a single incision ${ }^{2,4,7}$.

This alternative described herein attempts to reduce ergonomic problems, reduce surgical costs and facilitate the procedure on units with traditional laparoscopic equipment.

The techniques that use conventional straight clamps with single portal (disposable or permanent) have a significant reduction in range of motion. Similarly, the technique that uses three permanent trocars in a single incision improved range of motion, however, having three trocars with barrels (valves), collisions are inevitable, reducing the freedom of movement and hindering the procedure performance.

The improved ergonomics in this technical option has as its main cause the non-use of trocars for the $5 \mathrm{~mm}$ clamps, enabling the movement axis to be only the aponeurosis, greatly increasing the range of motion. When using the SILS trocar, the "single port" (three or more paths), the axis of movement of the grippers is a trocar having a 
length greater than the thickness of the aponeurosis, thereby limiting surgical mobility. It is worth noting, too, that the exchange of clamps through the lateral incisions without trocar is simple and there is no loss of pneumoperitoneum because the abdominal rectus muscle functions as a valve.
This alternative technique enables the laparoscopic cholecystectomy by single access, using only permanent and conventional materials, improving cosmetic results and with good ergonomics and comfort for the surgeon.

\section{R E S U M O}

Os autores descrevem uma técnica operatória que permite, sem aumento do custo, realizar a colecistectomia videolaparoscópicas, por única incisão, sem necessidade de utilizar materiais específicos, com melhor ergonomia cirúrgica. A técnica consiste na incisão umbilical longitudinal, descolamento de cicatriz umbilical, utilização de trocarter permanente de $10 \mathrm{~mm}$ e duas pinças atravessando diretamente a aponeurose bilateralmente sem uso de trocarteres de $5 \mathrm{~mm}$, reparo de vesícula biliar transcutânea com fio de algodão de agulha reta, ligadura com fio inabsorvível e extração de peça cirúrgica por incisão umbilical. A técnica apresentada viabiliza o procedimento com materiais convencionais e permanentes, melhora a ergonomia cirúrgica, com segurança e vantagens estéticas.

Descritores: Colecistectomia, Colecistectomia Laparoscópica. Cirurgia Videoassistida.

\section{REFERENCES}

1. Litynski GS. Profiles in laparoscopy: Mouret, Dubois, and Perissat: the laparoscopic breakthrough in Europe. JSLS. 1999;3(2):163-7.

2. Alves Júnior A, Oliveira IR, Lima MP, Barros AFV, Oliveira Filho JJ, Sobral HAC. Colecistectomia videolaparoscópica transumbilical (single site) com equipamento de laparoscopia convencional. J Port Gastrenterol. 2011;18(3):118-22.

3. Guarischi A. Videocirurgia em oncologia: mitos e verdades. Rev Col Bras Cir. 2007;34(5):283-4.

4. Pinheiro RN, Castro FMB, Sousa RC, Barreira CESR, Gouveia GC, Almeida RO. Single incision laparoscopic cholescystectomy: description of a series of 30 cases of laparoscopiv cholecystectomy performed using conventional instruments. Bras J Video-Sur. 2011;4(2):91-5.

5. Dávila ÁF, Tsin DA. Cirugía por orificios naturales (NOTES y manos) ¿La tercera revolución quirúrgica? Rev Mex Cir Endoscop. 2006; 7(1-4):6-13

6. Langwieler TE, Nimmesgern T, Back M. Single-port access in laparoscopic cholecystectomy. Sur Endosc. 2009;23(5):1138-41.
7. Galvão Neto M, Ramos A, Campos J. Single port laparoscopic access surgery. Tech Gastrointest Endosc. 2009;11(2):84-93.

8. Hong TH, You YK, Lee KH. Transumbilical single-port laparoscopic cholecystectomy: scarless cholecystectomy. Surg Endosc. 2009;23(6):1393-7.

9. Deveci U, Barbaros U, Kapakli MS, Manukyan MN, Simsek S, Kebudi $A$, et al. The comparison of single incision laparoscopic cholecystectomy and three port laparoscopic cholecystectomy: prospective randomized study. J Korean Surg Soc. 2013;85(6):27582.

Received at: 18/10/2014

Accepted for publication: 20/12/2014

Conflict of interest: none.

Source of funding: none.

Mailing address:

Marco Aurélio Lameirão Pinto

E-mail: marcoalp@globo.com 